\title{
PENERAPAN LOGIKA FUZZY DALAM MENENTUKAN JUMLAH PESERTA BPJS KESEHATAN MENGGUNAKAN FUZZY INFERENCE SYSTEM SUGENO
}

\author{
Rahmawati ${ }^{1}$, Ade Novia Rahma ${ }^{2}$, Irma Suryani ${ }^{3}$, Yusnita Sari ${ }^{4}$ \\ 1,2Universitas Islam Negeri Sultan Syarif Kasim Riau \\ $\underline{\text { rahmawati@uin-suska.ac.id }}{ }^{1}, \underline{\text { adenoviarahma_mufti@yahoo.com.id }}{ }^{2}, \underline{\text { irma.suryani@uin-suska.ac.id }}{ }^{3}$, \\ yusnitasari059@gmail.com ${ }^{4}$
}

\begin{abstract}
The purpose of this study is to determine the number of participants of the PBI on the Health BPJS Branch of Pekanbaru City. In this research, the method used FIS Sugeno is one of the Fuzzy Inference Systems. Stages-stages are carried out is to determine the set of fuzzy, implication functions, and defuzzification as well as the accuracy of forecasting. The results of this study showed that the number of participants of the PBI with variable input BPBI and Jamkesda and PJKMU health Insurance using the Method of FIS Sugeno has value accuracy achieve 94,17\%, this means that the results of the forecasting approach with the number of participants actually.
\end{abstract}

Keywords: Fuzzy Inference System, FIS Sugeno, BPJS Health, Revenue.

\begin{abstract}
Abstrak
Tujuan dari penelitian ini adalah untuk menentukan jumlah kepesertaan PBI pada BPJS Kesehatan Cabang Kota Pekanbaru. Dalam penelitian ini digunakan metode FIS Sugeno yang merupakan salah satu Fuzzy Inference System. Tahapan-tahapan yang dilakukan yaitu menentukan himpunan fuzzy, fungsi implikasi, dan defuzzyfikasi serta keakuratan peramalan. Hasil penelitian ini menunjukkan bahwa jumlah kepesertaan PBI dengan variable input BPBI dan Jamkesda dan PJKMU Askes menggunakan Metode FIS Sugeno memiliki nilai keakuratan yang mecapai $94,17 \%$, hal ini berarti hasil peramalan yang dilakukan mendekati dengan jumlah kepesertaan sebenarnya.
\end{abstract}

Kata kunci: Fuzzy Inference System, FIS Sugeno, BPJS Kesehatan, Pendapatan. 
Jurnal Lebesgue : Jurnal Ilmiah Pendidikan Matematika, Matematika dan Statistika

Rahmawati, Ade Novia Rahma, Irma Suryani, Yusnita Sari

Volume 1, No. 3, Desember 2020 hal.182-192

DOI Artikel : 10.46306/lb.v1i3.38

\section{PENDAHULUAN}

Permasalahan dibidang kesehatan acap kali timbul dalam suatu negara yang sedang berkembang. Negara dan pemerintah dituntut untuk menyediakan dan meningkatkan kebutuhan masyarakat khususnya dibidang kesehatan. Perlu adanya peningkatan kualitas pelayanan kesehatan sehingga mampu menanggulangi permasalahan kesehatan yang terjadi di masyarakat. Kebutuhan masyarakat terhadap kesehatan yang tidak dapat terpenuhi akan berdampak pada menurunnya taraf hidup masyarakat yang berakibat pada terjangkitnya penyakit dan permasalahan kesehatan lainnya. Badan Penyelenggara Jaminan Sosial (BPJS) Kesehatan hadir untuk memberikan jaminan sosial secara nasional dalam rangka memenuhi kebutuhan dasar yang layak bagi seluruh lapisan masyarakat berdasarkan asas kemanusiaan, manfaat, dan keadilan. BPJS Kesehatan merupakan sebuah lembaga yang menyediakan pelayanan asuransi kesehatan dengan menggunakan sistem premi asuransi. Dalam sistem premi asuransi mewajibkan setiap pesertanya untuk membayarkan iuran sesuai dengan kelas yang dipilih (Azrul, 2009).

Sistem jaminan sosial nasional merupakan program negara yang bertujuan memberikan kepastian jaminan yang lebih menyeluruh dan terpadu bagi setiap masyarakat Indonesia agar dapat hidup sehat, produktif, dan sejahtera. Undang-Undang No. 24 Tahun 2011 juga menetapkan, jaminan sosial nasional akan diselenggarakan oleh BPJS, yang terdiri dari BPJS Ketenagakerjaan dan BPJS Kesehatan. Pada tahun 2004 pemerintah mengeluarkan UU Nomor 40 Tahun 2004 tentang Sistem Jaminan Sosial Nasional (SJSN) dan kemudian pada tahun 2011 pemerintah menetapkan UU Nomor 24 Tahun 2011 tentang Badan Penyelenggara Jaminan Sosial (BPJS) serta menunjuk PT Askes (Persero) sebagai penyelenggara program jaminan sosial di bidang kesehatan, sehingga PT Askes (Persero) pun berubah menjadi BPJS Kesehatan. BPJS adalah peleburan 4 (empat) badan usaha milik negara menjadi satu badan hukum, 4 (empat) badan usaha yang dimaksud adalah PT TASPEN, PT JAMSOSTEK, PT ASABRI, dan PT ASKES. Badan Penyelenggara Jaminan Sosial ini berbentuk seperti asuransi, nantinya semua warga indonesia diwajibkan untuk mengikuti program ini. Dalam mengikuti program ini peserta BPJS di bagi menjadi 2 kelompok, yaitu untuk mayarakat yang mampu dan kelompok masyarakat yang kurang mampu. Peserta kelompok BPJS di bagi 2 kelompok yaitu:

a. Penerima Bantuan Iuran (PBI) jaminan kesehatan, yaitu peserta Jaminan Kesehatan bagi fakir miskin dan orang tidak mampu sebagaimana diamanatkan Undang-undang SJSN yang iurannya dibayarkan oleh pemerintah sebagai peserta program Jaminan Kesehatan. Peserta PBI adalah fakir miskin yang ditetapkan oleh pemerintah dan diatur melalui Peraturan Pemerintah.

b. Bukan Penerima Bantuan Iuran (BPBI) jaminan kesehatan, yaitu peserta yang terdiri dari, Pekerja penerima upah dan anggota keluarganya, pekerja bukan penerima upah dan anggota keluarganya, bukan pekerja dan anggota keluarganya.

Logika Fuzzy adalah peningkatan dari logika Boolean yang berhadapan dengan konsep kebenaran sebagian. Saat logika klasik menyatakan segala hal dapat didefinisikan dalam istilah biner(0 atau 1, hitam 
Jurnal Lebesgue : Jurnal Ilmiah Pendidikan Matematika, Matematika dan Statistika

Rahmawati, Ade Novia Rahma, Irma Suryani, Yusnita Sari

Volume 1, No. 3, Desember 2020 hal.182-192

DOI Artikel : 10.46306/lb.v1i3.38

atau putih, ya atau tidak), logika fuzzy menggantikan kebenaran Boolean dengan tingkat kebenaran. Fuzzy Inference System (FIS) Sugeno merupakan salah satu metode penyambilan keputusan dalam logika fuzzy. Metode ini diperkenalkan oleh Takagi-Sugeno Kang pada tahun 1985. FIS Sugeno memperbaiki kelemahan yang dimiliki oleh sistem fuzzy murni untuk menambah suatu perhitungan matematika sederhana sebagai bagian THEN. Pada perubahan ini, sistem fuzzy memiliki suatu nilai rata-rata tertimbang (Weighted Average Values) di dalam bagian aturan fuzzy IF-THEN. FIS Sugeno juga memiliki kelemahan terutama pada bagian THEN, yaitu dengan adanya perhitungan matematika sehingga tidak dapat menyediakan kerangka alami untuk merepresentasikan pengetahuan manusia dengan sebenarnya. Permasalahan kedua adalah tidak adanyakebebasan untuk menggunakan prinsip yang berbeda dalam logika fuzzy, sehingga ketidak pastian dari sistem fuzzy tidak dapat direpresentasikan secara baik (Naba, 2009).

Beberapa penelitian sebelumnya yang telah menggunakan FIS Sugeno ini diantaranya, yaitu (Dorteus, 2015) menentukan jumlah produksi roti berdasarkan data Persediaan dan jumlah permintaan, dengan hasil MSE untuk Metode Sugeno sebesar 86,92\%. Kemudian (Sitio, 2018) menerapkan metode FIS Sugeno untuk mengetahui jumlah pembelian obat di Garuda Sentra Medika berdasarkan data persediaan dan data penjualan. Dari penelitian tersebut peneliti menyimpulkan bahwa hasil uji coba yang dilakukan dengan metode FIS Sugeno, maka tingkat keberhasilan dalam menentukan pembelian obat mencapai $88,02 \%$ dari 20 jenis data obat yang dipilih secara acak. Dalam hal ini penulis menenutukan jumlah Kepesertaan BPJS Kesehatan Cab. Nangka Kota Pekanbaru pada tahun 2017. Dalam penelitian ini, juga akan menggunakan Metode FIS Sugeno untuk menentukan jumlah kepesertaan PBI pada BPJS Kesehtan Cab. Kota Pekanbaru yang berdasarkan pada jumlah kepesertaan Bukan Penerima Bantuan Iuran (BPBI) dan Jamkesda dan Program Jaminan Kesehatan Masyarakat Umum (PJKMU) Askes.

\section{METODE PENELITIAN}

Dalam menentukan peramalan jumlah kepesertaan BPJS kesehatan, diperlukan beberapa tahapan, pertama yaitu mencari dan menganalisa data internal yang diperoleh dari data internal BPJS Kesehatan cab. Kota Pekanbaru, pembentukan himpunan fuzzy, menentukan fungsi implikasi, defuzzyfikasi serta mengecek keakuratan peramalan. (Kusumadewi, 2009) mengasumsikan bahwa metode fuzzy Sugeno merupakan usaha untuk mengembangkan pendekatan sistematis untuk membangun aturan samar atau fuzzy dari himpunan data input dan output. Metode FIS Sugeno menggunakan konstanta atau fungsi matematika dari variabel input :

Jika $a$ adalah $\tilde{A}_{i}$ dan $b$ adalah $\tilde{B}_{i}$, maka $c$ adalah $\tilde{C}=f(a, b)$

dengan $a, b$ dan $c$ adalah variabel linguistik, $\tilde{A}_{i}$ dan $\tilde{B}_{i}$ himpunan fuzzy ke- $i$ untuk $a$ dan $b$, dan $f(a, b)$ adalah fungsi matematik. Untuk mendapatkan hasil, maka terdapat 3 langkah tahapan sebagai berikut: 
Jurnal Lebesgue : Jurnal Ilmiah Pendidikan Matematika, Matematika dan Statistika

Rahmawati, Ade Novia Rahma, Irma Suryani, Yusnita Sari

Volume 1, No. 3, Desember 2020 hal.182-192

DOI Artikel : 10.46306/lb.v1i3.38

a. Pembentukan himpunan fuzzy

Menentukan semua variabel yang terkait dalam proses yang akan ditentukan. Untuk masingmasing variabel input, tentukan suatu fungsi fuzzifikasi yang sesuai. Pada metode FIS Sugeno, baik variabel input maupun variabel output dibagi menjadi satu atau lebih himpunan fuzzy.

b. Aplikasi Fungsi Implikasi

Menyusun basis aturan, yaitu aturan-aturan berupa implikasi-implikasi fuzzy yang menyatakan relasi antara variabel input dengan variabel output. Pada metode FIS Sugeno, fungsi implikasi yang digunakan adalah Min. Bentuk umumnya adalah sebagai berikut :

Jika $a$ adalah $\tilde{A}_{i}$ dan $b$ adalah $\tilde{B}_{i}$, maka $c$ adalah $\tilde{C}$

dengan $a, b$ dan $c$ adalah variabel linguistik ; $\tilde{A}_{i}$ dan $\tilde{B}_{i}$ himpunan fuzzy ke-i untuk $a$ dan $b$, dan $\tilde{C}$ adalah fungsi matematik. Banyaknya aturan ditentukan oleh banyaknya nilai linguistik untuk masingmasing variabel input. Solusi himpunan fuzzy pada metode ini mengaplikasikannya ke output dengan menggunakan operator AND. Jika semua proporsi telah dievaluasi, maka output akan berisi suatu himpunan fuzzy yang merefleksikan kontribusi dari tiap-tiap proporsi. Secara umum dapat dituliskan :

$$
\mu_{A \cap B}=\min \left(\mu_{A}\left(x_{i}\right), \mu_{B}\left(y_{i}\right)\right)
$$

$\mu_{A}\left(x_{i}\right)=$ nilai keanggotaan solusi fuzzy sampai aturan ke- $i$

$\mu_{B}\left(y_{i}\right)=$ nilai keanggotaan konsekuen fuzzy aturan ke- $i$.

\section{c. Penegasan (Defuzzyfikasi)}

Masukan dari proses penegasan adalah suatu himpunan fuzzy yang diperoleh dari komposisi aturan-aturan fuzzy, sedangkan output yang dihasilkan merupakan suatu bilangan real yang tegas. Sehingga jika diberikan suatu himpunan fuzzy dalam range tertentu, maka dapat diambil suatu nilai tegas tertentu sebagai output. Berdasarkan (Dorteus, 2015) pada metode FIS Sugeno, defuzzifikasi dilakukan dengan cara mencari nilai rata-rata terpusatnya yaitu

$$
W A=\frac{\sum_{i=1}^{n} d_{i} \mu_{\widetilde{A}_{i}}\left(d_{i}\right)}{\sum_{i=1}^{n} \mu_{\widetilde{A}_{i}}\left(d_{i}\right)}
$$

dengan $d_{i}$ adalah nilai keluaran pada aturan ke- $i$ dan $\mu_{\tilde{A}_{i}}\left(d_{i}\right)$ adalah derajat keanggotaan nilai keluaran pada aturan ke- $i$ sedangkan $n$ adalah banyaknya aturan yang digunakan.

Apabila ingin menentukan keakuratan model, maka dapat menggunakan MSE (Mean Square Error) dan MAPE (Mean Absolute Percentage Error). MSE merupakan kriteria prediksi dengan mengkuadratkan setiap error dan dibagi sebanyak jumlah data. Bentuk persamaanya sebagai berikut :

$$
M S E=\frac{\sum_{i=1}^{n}\left(z_{i}-\hat{z}_{i}\right)^{2}}{n}
$$

sedangkan MAPE merupakan suatu ukuran akurasi peramalan dari suatu metode peramalan. Hasilnya yang berbentuk persentase kemudian dimutlakkan. Hasil peramalan sangat bagus jika nilai MAPE 
Jurnal Lebesgue : Jurnal Ilmiah Pendidikan Matematika, Matematika dan Statistika

Rahmawati, Ade Novia Rahma, Irma Suryani, Yusnita Sari

Volume 1, No. 3, Desember 2020 hal.182-192

DOI Artikel : 10.46306/lb.v1i3.38

kurang dari $10 \%$ sedangkan nilai MAPE dikatakan bagus jika kurang dari 20\% . MAPE didefinisikan sebagai berikut :

$$
M A P E=\frac{\sum_{i=1}^{n}\left(\frac{z_{i}-\hat{z}_{i}}{z_{i}}\right) \times 100 \%}{n}
$$

dengan :

$z_{i}=$ nilai data asli amatan ke- $i$

$\hat{z}_{i}=$ nilai ramalan amatan ke- $i$

$n=$ banyaknya data

Setelah memperoleh nilai MAPE untuk mengetahui nilai kebenarannya dapat dilakukan dengan :

$$
\text { Tingkat Kebenaran }=100 \%-\text { MAPE }
$$

Kriteria nilai MAPE menurut (Chang et al., 2007)adalah :

1. $<10 \%$ (kemampuan peramalan sangat baik)

2. $10 \%-20 \%$ (kemampuan peramalan baik)

3. $20 \%-50 \%$ (kemampuan peramalan cukup)

4. $>50 \%$ (kemampuan peramalan buruk).

Namun menurut (Makridakis, 1999), model yang tepat adalah model yang memiliki nilai MAPE sekitar 0\%-30\%. Jadi, dapat disimpulkan nilai MAPE 0\% minimal cukup dan maksimal 30\% untuk dijadikan sebagai input dari metode fuzzy.

\section{HASIL DAN PEMBAHASAN}

Dalam Penyelesaian masalah menentukan optimasi jumlah kepesertaan Penerima Bantuan Iuran (PBI) pada BPJS Kesehatan cab. Kota Pekanbaru yaitu menggunakan variable input data jumlah peserta Bukan Penerima Bantuan Iuran (BPBI) serta peserta Jamkesda dan Program Jaminan Kesehatan Masyarakat Umum (PJKMU) Askes diberikan pada Tabel 1 berikut.

Tabel 1. Data Penerima Bantuan Iuran (BPI), Bukan Penerima Bantuan Iuran (BPBI), dan Jamkesda \& PJKMU Askes di BPJS Kesehatan Cab.Kota Pekanbaru

\begin{tabular}{|c|c|c|c|}
\hline \multirow{2}{*}{ Bulan } & $\begin{array}{c}\text { Penerima Bantuan } \\
\text { Iuran (PBI) } \\
\text { (dalam Jiwa) }\end{array}$ & $\begin{array}{c}\text { Bukan Penerima } \\
\text { Bantuan Iuran } \\
\text { (BPBI) (dalam } \\
\text { Jiwa) }\end{array}$ & $\begin{array}{c}\text { Jamkesda \& } \\
\text { PJKMU Askes } \\
\text { (dalam Jiwa) }\end{array}$ \\
\hline Januari/2017 & 148.947 & 341.886 & 42.747 \\
\hline
\end{tabular}


Jurnal Lebesgue : Jurnal Ilmiah Pendidikan Matematika, Matematika dan Statistika

Rahmawati, Ade Novia Rahma, Irma Suryani, Yusnita Sari

Volume 1, No. 3, Desember 2020 hal.182-192

DOI Artikel : 10.46306/lb.v1i3.38

\begin{tabular}{|l|l|l|l|}
\hline Februari/2017 & 148.907 & 340.532 & 42.719 \\
\hline Maret/2017 & 148.868 & 342.814 & 42.715 \\
\hline Apri1/2017 & 148.823 & 347.362 & 42.708 \\
\hline Mei/2017 & 148.827 & 349.364 & 42.652 \\
\hline Juni/2017 & 148.805 & 349.993 & 42.609 \\
\hline Juli/2017 & 149.097 & 350.033 & 42.644 \\
\hline Agustus/2017 & 149.150 & 349.978 & 42.610 \\
\hline September/2017 & 149.361 & 352.938 & 42.558 \\
\hline Oktober/2017 & 149.345 & 357.049 & 42.201 \\
\hline November/2017 & 149.733 & 359.199 & 41.924 \\
\hline Deesember/2017 & 149.840 & 360.936 & 42.701 \\
\hline
\end{tabular}

Sumber : BPJS Kesehatan cab. Kota Pekanbaru.

Dari bahan penelitian yang telah didapatkan maka dilakukan perhitungan dengan mengambil nilai minimal dan maksimal dari variabel input maupun output dapat dilihat dari Tabel 2 berikut :

Tabel 2. Nilai Minimal dan Maksimal dari Variabel Input dan Output

\begin{tabular}{|c|c|c|}
\hline Fungsi & Nama Variabel & Domain (jiwa) \\
\hline \multirow{3}{*}{ Input } & Bukan Penerima Bantuan & {$[340.532-360.936]$} \\
& Iuran (BPBI) & {$[41.924-42.747]$} \\
\cline { 2 - 3 } & Jamkesda \& PJKMU Askes & {$[148.805-149.840]$} \\
\hline \multirow{2}{*}{ Output } & Penerima Bantuan Iuran & \\
\hline
\end{tabular}

Telah ditentukan pembentukan aturan output dengan menganalisa data terhadap domain serta himpunan fuzzy serta nilai lingiuistik sehingga terdapat aturan fuzzy berikut ini :

[R1] JIKA BPBI Turun dan Jamkesda \& PJKMU Askes Sedikit, MAKA PBI Sedikit

[R2] JIKA BPBI Turun dan Jamkesda \& PJKMU Askes Banyak, MAKA PBI Sedikit

[R3] JIKA BPBI Naik dan Jamkesda \& PJKMU Askes Sedikit, MAKA PBI Banyak

[R4] JIKA BPBI Naik dan Jamkesda \& PJKMU Askes BPBI Banyak, MAKA PBI Banyak.

Masalah diatas diselesaikan menggunakan Metode FIS Sugeno dengan tahap-tahap berikut ini :

Langkah 1. Pembentukan Himpunan fuzzy

Menentukan variabel yang terkait dalam proses yang akan ditentukan dan fungsi fuzzifikasi yang sesuai. Berikut adalah himpunan fuzzy masing-masing variabel mengunakan Metode FIS Sugeno:

a. Bukan Penerima Bantuan Iuran (BPBI) $(x)$, dengan nilai linguistik yaitu Turun dan Naik.

b. Jamkesda \& PJKMU Askes ( $y$ ), dengan nilai linguistik yaitu Sedikit dan Banyak.

c. Penerima Bantuan Iuran (PBI)(z), dengan nilai linguistik yaitu Sedikit dan Banyak. 
Langkah 2. Aplikasi Fungsi Implikasi dan Komposisi Aturan

Berikut adalah cara untuk mendapatkan nilai keanggotan berdasarkan variabel linguistik dan variabel numerik yang digunakan:

- Fungsi keanggotaan himpunan Fuzzy dari variabel Bukan Penerima Bantuan Iuran (BPBI)

$$
\begin{aligned}
& \mu \text { BPBI Turun }(\mathrm{x})=\left\{\begin{array}{clc}
1 & ; & \mathrm{x}<340.532 \\
\frac{360.936-x}{360.936-340.532} & ; 340.532 \leq \mathrm{x} \leq 360.936 \\
0 & ; \quad x>360.936
\end{array}\right. \\
& \mu \text { BPBI Naik }(\mathrm{x})=\left\{\begin{array}{llc}
1 & ; & \mathrm{x}<340.532 \\
\frac{x-340.532}{360.936-340.532} & ; 340.532 \leq \mathrm{x} \leq 360.936 \\
0 & ; & \mathrm{x}>360.936
\end{array}\right.
\end{aligned}
$$

- Fungsi keanggotaan himpunan fuzzy dari Jamkesda \& PJKMU Askes yaitu

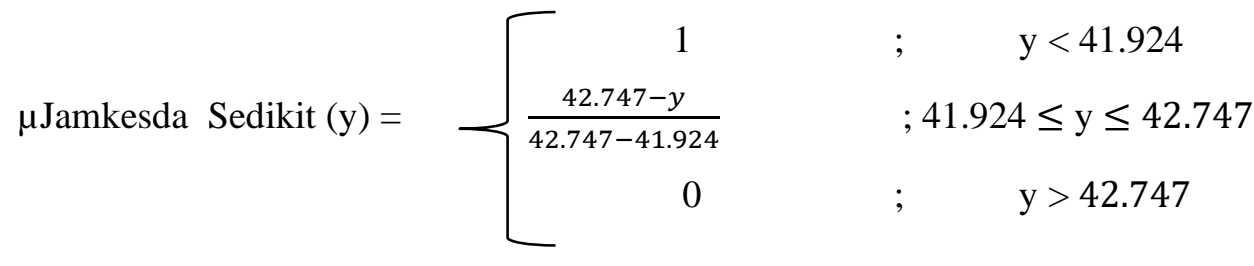

$$
\begin{aligned}
& \mu \text { Jamkesda Banyak }(y)=\left\{\begin{array}{clc}
1 & ; & \mathrm{y}<41.924 \\
\frac{y-41.924}{42.747-41.924} & ; 41.924 \leq \mathrm{y} \leq 42.747 \\
0 & ; \quad \mathrm{y}>42.747 .
\end{array}\right.
\end{aligned}
$$

\section{Langkah 3. Defuzzifikasi atau Penegasan}

Selanjutnya defuzzifikasi dilakukan untuk menentukan keluaran berupa produksi barang untuk setiap bulannya sesuai data. Berikut diberikan analisis Himpunan Fuzzy pada Bulan Januari Tahun 2017.

$$
\begin{array}{ll}
\text { Jumlah BPBI } & : 341.886 \\
\text { Jumlah Jamkesda } & : 42.747
\end{array}
$$
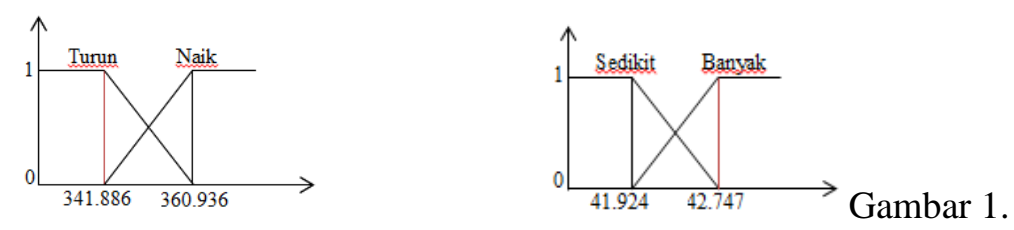

Gambar 1. Himpunan Fuzzy pada Bulan Januari Tahun 2017. 
Berdasarkan himpunan fuzzy jumlah BPBI yaitu Turun dan Naik, sedangkan himpunan fuzzy jumlah Jamkesda berada pada titik Sedikit dan Banyak. Derajat keanggotaannya dapat diperoleh sebagai berikut :

$$
\begin{aligned}
& \mu_{B P B I \text { Turun }}(341.886)=\frac{360.936-341.886}{360.936-340.532}=\frac{18.646}{20.404}=0,93 \\
& \mu_{B P B I \text { Naik }}(341.886)=\frac{360.936-341.886}{360.936-340.532}=\frac{1354}{20.404}=0,07
\end{aligned}
$$

dan jika diketahui Jamkesda sebanyak 42.747 , maka :

$$
\begin{aligned}
& \mu_{\text {JamkesdaSedikit }}(42.747)=\frac{42.747-42.747}{42.747-41.924}=\frac{0}{823}=0 \\
& \mu_{\text {Jamkesda Banyak }}(42.747)=\frac{42.747-41.924}{42.747-41.924}=\frac{823}{823}=1
\end{aligned}
$$

Selanjutnya aturan- aturan yang dapat digunakan serta mencari $\alpha$-predikat menggunakan aturanaturan fuzzy yang telah ditentukan dan Persamaan (1) yaitu sebagai berikut :

[R1] JIKA BPBI Turun, dan Jamkesda Sedikit, MAKA PBI Sedikit;

$$
\begin{aligned}
\alpha-\text { predikat } 1 & =\mu_{B P B I} \text { Turun } \cap \mu_{\text {Jamkesda Sedikit }} \\
& =\left(\mu_{B P B I} \text { Turun }((341.886)), \mu_{\text {Jamkesdasedikit }}(42.747)\right) \\
& =\min ((0,93 ; 0)) \\
& =0
\end{aligned}
$$

[R2] JIKA BPBI Turun, dan Jamkesda Banyak, MAKA PBI Sedikit;

$$
\begin{aligned}
\alpha \text { - predikat } 2 & =\mu_{\text {BPBI Turun }} \cap \mu_{\text {Jamkesda banyak }} \\
& =\left(\mu_{\text {BPBI Turun }}((341.886)), \mu_{\text {Jamkesda Banyak }}(42.747)\right) \\
& =\min (0,93 ; 1) \\
& =0,93
\end{aligned}
$$

[R3] JIKA BPBI Naik, dan Jamkesda Sedikit, MAKA PBI Banyak;

$$
\begin{aligned}
\alpha-\text { predikat } 2 & =\mu_{B P B I \text { Naik }} \cap \mu_{\text {JamkesdaSedikit }} \\
& =\left(\mu_{B P B I \text { Naik }}((341.886)), \mu_{\text {Jamkesda Sedikit }}(42.747)\right) \\
& =\min (0,07 ; 0) \\
& =0
\end{aligned}
$$

[R4] JIKA BPBI Naik, dan Jamkesda Banyak, MAKA PBI Banyak;

$\alpha$ - predikat $2=\mu_{B P B I \text { Naik }} \cap \mu_{\text {Jamkesda Banyak }}$ 
Jurnal Lebesgue : Jurnal Ilmiah Pendidikan Matematika, Matematika dan Statistika

Rahmawati, Ade Novia Rahma, Irma Suryani, Yusnita Sari

Volume 1, No. 3, Desember 2020 hal.182-192

DOI Artikel : 10.46306/lb.v1i3.38

$$
\begin{aligned}
& =\left(\mu_{B P B I \text { Naik }}((341.886)), \mu_{\text {Jamkesda Banyak }}(342.747)\right) \\
& =\min (0,07 ; 1) \\
& =0,07
\end{aligned}
$$

Selanjutnya untuk memperoleh nilai kesimpulan dari defuzzifikasi, digunakan Persamaan (2) yaitu sebagai berikut :

$$
\begin{aligned}
W A & =\frac{\sum_{i=1}^{n} d_{i} \mu_{\tilde{A}_{i}}\left(d_{i}\right)}{\sum_{i=1}^{n} \mu_{\tilde{A}_{i}}\left(d_{i}\right)} \\
& =\frac{0(148.805)+0,93(148.805)+0(149.840)+0,07(149.840)}{0+0,93+0+0,07} \\
& =\frac{0+138.388,65+0+10.488,8}{0+0,93+0+0,07} \\
& =\frac{242.887,45}{1} \\
& =242.887,45
\end{aligned}
$$

maka diperoleh banyaknya peserta PBI menggunakan metode fuzzy Sugeno pada bulan Januari Tahun 2017 adalah: 242.887,45.

Dengan menggunakan cara yang sama untuk tiap bulan selanjutnya, maka diperoleh hasil prediksi jumlah kepesertaan PBI berdasar metode FIS Sugeno yang diberikan pada Tabel 3 berikut.

Tabel 3. Jumlah yang diprediksi berdasarkan input Jumlah Kepesertaan BPJS Kesehatan.

\begin{tabular}{|l|c|c|c|c|}
\hline \multicolumn{1}{|c|}{ Bulan } & $\begin{array}{c}\text { Penerima } \\
\text { Bantuan } \\
\text { Iuran (PBI) }\end{array}$ & $\begin{array}{c}\text { Bukan Penerima } \\
\text { Bantuan Iuran } \\
\text { (BPBI) }\end{array}$ & $\begin{array}{c}\text { Jamkesda \& } \\
\text { PJKMU Askes }\end{array}$ & $\begin{array}{c}\text { Fuzzy } \\
\text { Sugeno } \\
\text { untuk PBI }\end{array}$ \\
\hline Januari/2017 & 148.947 & 341.886 & 42.747 & $242.877,45$ \\
\hline Februari/2017 & 148.907 & 340.532 & 42.719 & 143.805 \\
\hline Maret/2017 & 148.868 & 342.814 & 42.715 & $148.948,75$ \\
\hline April/2017 & 148.823 & 347.362 & 42.708 & $147.819,19$ \\
\hline Mei/2017 & 148.827 & 349.364 & 42.652 & $149.271,60$ \\
\hline Juni/2017 & 148.805 & 349.993 & 42.609 & $149.291,61$ \\
\hline Juli/2017 & 149.097 & 350.033 & 42.644 & $149.289,12$ \\
\hline Agustus/2017 & 149.150 & 349.978 & 42.610 & $149.291,61$ \\
\hline September/2017 & 149.361 & 352.938 & 42.558 & $149.393,40$ \\
\hline Oktober/2017 & 149.345 & 357.049 & 42.201 & $146.656,45$ \\
\hline November/2017 & 149.733 & 359.199 & 41.924 & $149.757,2$ \\
\hline Deesember/2017 & 149.840 & 360.936 & 42.701 & 149.840 \\
\hline
\end{tabular}


Jurnal Lebesgue : Jurnal Ilmiah Pendidikan Matematika, Matematika dan Statistika

Rahmawati, Ade Novia Rahma, Irma Suryani, Yusnita Sari

Volume 1, No. 3, Desember 2020 hal.182-192

DOI Artikel : 10.46306/lb.v1i3.38

Berdasarkan hasil dari metode FIS Sugeno maka didapat jumlah kepesertaan PBIdi BPJS Kesehatan cab. Kota Pekanbaru mengggunakan persentase rata—rata atau Mean Absolute Precentage (MAPE) sebagai berikut.

Tabel 5. Tabel Perhitungan MAPE Jumlah Pendapatan dengan Metode Fuzzy Sugeno dari tahun 2017.

\begin{tabular}{|c|c|c|c|}
\hline PBI $\left(Z_{t}\right)$ & PBI Sugeno $\left(\hat{Z}_{t}\right)$ & $\begin{array}{c}\text { Error } \\
\left|Z_{t}-\hat{Z}_{t}\right|\end{array}$ & $\frac{Z_{t}-\hat{Z}_{t}}{Z_{t}} \times 100 \%$ \\
\hline 148.947 & $242.877,45$ & 93,930 & 63,063 \\
\hline 148.907 & 143.805 & 5,102 & 3,4263 \\
\hline 148.868 & $148.948,75$ & 0,080 & 0,054 \\
\hline 148.823 & $147.819,19$ & 1,003 & 0,674 \\
\hline 148.827 & $149.271,60$ & 0.444 & 0,298 \\
\hline 148.805 & $149.291,61$ & 0,486 & 0,327 \\
\hline 149.097 & $149.289,12$ & 0,192 & 0,128 \\
\hline 149.150 & $149.291,61$ & 0,141 & 0,094 \\
\hline 149.361 & $149.393,40$ & 0,032 & 0,021 \\
\hline 149.345 & $146.656,45$ & 2,688 & 1,800 \\
\hline 149.733 & $149.757,2$ & 0,024 & 0,016 \\
\hline 149.840 & 149.840 & 0 & 0 \\
\hline
\end{tabular}

Langkah 4. Akurasi Peramalan

Selanjutnya Perhitungan MAPE metode FIS Sugeno sebagai berikut :

$$
M A P E=\frac{\sum_{t=1}^{n}\left(Z_{t}-\hat{Z}_{t}\right) \times 100 \%}{Z_{t}}=\frac{69,928}{12}=5,83 \% \text {. }
$$

Selanjutnya untuk memperoleh tingkat kebenaran metode FIS Sugeno yang dipakai yaitu :

$$
100 \%-5,83 \%=94,17 \% \text {. }
$$

Sehingga didapat hasil perhitungan rata-rata persentase kesalahan dari metode FIS Sugeno yang digunakan adalah 5,83\% sedangkan tingkat kebenaran dari hasil perhitungan tersebut adalah $94,17 \%$.

\section{KESIMPULAN}

Berdasarkan pembahasan yang telah dilakukan, dapat diambil kesimpulan bahwa tingkat kebenaran dari hasil perhitungan jumlah kepesertaan PBI menggunakan Metode FIS Sugeno dengan variable input BPBI dan Jamkesda \& PJKMU Askes sebesar 94,17\% yang berarti bahwa peramalan 
Jurnal Lebesgue : Jurnal Ilmiah Pendidikan Matematika, Matematika dan Statistika

Rahmawati, Ade Novia Rahma, Irma Suryani, Yusnita Sari

Volume 1, No. 3, Desember 2020 hal.182-192

DOI Artikel : 10.46306/lb.v1i3.38

menggunakan metode ini sangatlah tepat karena hasil yang diperoleh mendekati jumlah PBI yang sebenarnya.

\section{DAFTAR PUSTAKA}

Azrul, A. (2009). Program Menjaga Mutu Pelayanan Kesehatan. Yayasan Penerbitan IDI.

Chang, P. C., Wang, Y. W., \& Liu, C. H. (2007). The development of a weighted evolving fuzzy neural network for PCB sales forecasting. Expert Systems with Applications, 32(1), 8696. https://doi.org/10.1016/j.eswa.2005.11.021

Dorteus, L. R. (2015). Penerapan Logika Fuzzy Metode Sugeno Berdasarkan Data Persediaan Dan Jumlah Permintaan ( Studi Kasus : Pabrik Roti Sarinda Ambon ). Jurnal Ilmu Matematika Dan Terapan, 9(2), 121-134.

https://ojs3.unpatti.ac.id/index.php/barekeng/article/view/289/249

Kusumadewi, S. (2009). Aplikasi Logika Fuzzy untuk Pendukung Pengambilan Keputusan. Graha Ilmu.

Makridakis, S. et al. (1999). Metode dan aplikasi peramalan, (U.S. Andriyanto dan A. Basith, terj.) (Jilid 1). Erlangga.

Naba, D. E. . (2009). Belajar Cepat Fuzzy Logic Menggunakan Matlab. Andi Publisher.

Sitio, S. L. M. (2018). Penerapan Fuzzy Inference System Sugeno untuk Menentukan Jumlah Pembelian Obat (Studi Kasus: Garuda Sentra Medika). Jurnal Informatika Universitas Pamulang, 3(2), 104. https://doi.org/10.32493/informatika.v3i2.1522. 